\title{
Biomimetic Approaches for Adaptive Building Envelopes: Applications and Design Considerations
}

\author{
Riham Nady Faragllah
}

Faculty of Engineering, Pharos University in Alexandria, Egypt

Received February 10, 2021; Revised June 24, 2021; Accepted October 15, 2021

\section{Cite This Paper in the following Citation Styles}

(a): [1] Riham Nady Faragllah , "Biomimetic Approaches for Adaptive Building Envelopes: Applications and Design Considerations," Civil Engineering and Architecture, Vol. 9, No. 7, pp. 2464 - 2475, 2021. DOI: 10.13189/сеа.2021.090731.

(b): Riham Nady Faragllah (2021). Biomimetic Approaches for Adaptive Building Envelopes: Applications and Design Considerations. Civil Engineering and Architecture, 9(7), 2464 - 2475. DOI: 10.13189/cea.2021.090731.

Copyright@2021 by authors, all rights reserved. Authors agree that this article remains permanently open access under the terms of the Creative Commons Attribution License 4.0 International License

\begin{abstract}
In the past decade, the evolution of biomimicry architecture was considered as an important issue for achieving adaptation strategies to cope with the different climatic aspects and to provide thermal comfort inside buildings which suit various environmental conditions. Egypt is one of the countries that faces the problem of using excessive energy to cool buildings due to weak building envelopes especially during the summer season that needs to be solved through biomimicry design approaches. The paper assumes that the role of nature design has a significant influence to promote occupants' comfort, ensure energy conservation of the building and can be seen as an important contribution to sustainability of the built environment. The paper presents the concept and development of biomimicry architecture and its impact on building envelopes. Then, it analyses different biomimetic design applications in hot arid climates to conclude adaptable design considerations that are flexible and responds to differences in their surrounding context. Finally, the third part concludes a biomimicry design matrix for building envelopes that can act as a road map for adaptive implementations. The scope of the paper is the study and analysis of biomimicry as an important tool for architectural design and sustainable construction focusing on the possibility of applying biomimetic principles for adaptive building envelopes describing their potential for future building design in hot arid regions.
\end{abstract}

Keywords Adaptive, Biomimetic, Design, Envelope, Hot Arid, Nature, Sustainability

\section{Introduction}

Buildings act as a considerable environmental problem because they are responsible for relatively $23 \%$ of the world's total basic energy usage and $30 \%$ of the global electricity consumption. According to the International Energy Agency (IEA), the global total energy consumption in buildings has increased by $48 \%$ due to space heating and cooling loads [1]. In other words, the construction industry is the biggest consumer of energy as it is accountable for more than one-third of all energy consumed and one-half of global power usage. It is expected that growth in the population, as well as the increased demand for building facilities and services, estimated high levels of satisfaction, and increased time spent within buildings, will increase energy consumption in the future [2].

As a result, there is an urgent need to design adaptive building envelopes and prioritise energy efficiency over resource depletion and related negative environmental consequences. A building envelope has been traditionally thought of as a thermal membrane which prevents heat loss and controls heat gain. In this context, the building envelope becomes responsible with a major part to control climate, energy consumption and human comfort inside the building. The envelope is commonly understood as a basic factor which affects the consumption of energy inside a building. Design variables (orientation of the outside wall) or design inputs provided by the surrounding (the outdoor temperature of the site) may affect the energy output of the building envelope.

In fact, most building envelopes within contemporary 
architecture are designed to provide "static" design solutions that lack the ability to adapt to local climatic problems and environmental needs. Thus, there is a growing concern to transform building envelopes from "static" to "dynamic" to enhance energy performance and promote indoor thermal comfort. These goals require new concepts, materials, auspicious strategies and technologies to enhance the building energy efficiency and to encourage the design of a sensitive building envelope with responsive and dynamic techniques. The key feature of this concept is to equip buildings with elements and systems that can always respond to weather changes and the demand of building users [3].

The design of a building envelope determines its thermal comfort in spaces. In hot and dry climate areas, occupants indicate a rising need for energy to run air conditioning systems. Thus, this technique contributes to the development of "sick building syndrome" and harms the surrounding context.

To achieve a more sustainable built environment, nature and biomimicry concepts provide guidelines and strategies for improving and adapting building envelopes in different terms such as energy efficiency, lighting, temperature, ... etc. This means that, in order to construct energy efficient building envelopes, it is important to learn from natural organisms and to mimic their useful relevant treatments [4].

The main problem is the current existing buildings in the Egyptian context that have week building envelopes and are inefficiently "sealed" making them more susceptible to heat loss and heat gain. This is translated into low energy efficiency, as more energy is needed to maintain thermal comfort in buildings while also compensating for this leakage.

The hypothesis of the paper focuses on the core concepts about the significance of biomimetics in architecture and the role of nature design in adapting the built environment to clarify different approaches of biomimetic design. This can be made clear by analysing and comparing different examples in hot regions such as Eastgate Center in Zimbabwee, Ministry of Municipal Affairs and Agriculture
Office in Qatar and the Council House 2 in Melbourne. These examples and applications present how these building envelopes were designed taking into consideration the objectives of the biomimetic concerns and users' needs. This will help to reach the biomimetic design considerations and sustainable approaches for adaptive building envelopes that are appropriate and successful.

The methodology of the paper is an analytical deduction that is divided into three parts. The first part is a literature review that presents the concept and history of biomimicry, approaches and levels. Also, it discusses the development of building envelopes and explores the natural design measures and approaches that influence the construction of different adaptable building envelopes. Then, the paper moves to the second part that analyses different biomimicry applications that use biomimetic adaptive techniques through building envelopes exploring several terms such as heat, air, water, light, ... etc. to conclude the main biomimetic design considerations that would help in the design of adaptive building envelopes particularly in hot regions. Finally, the third part proposes a design matrix for flexible approaches and biomimetic building systems that could be adopted by architects and designers during the design stage especially in the hot arid environments so that it could be applicable applied to buildings in the Egyptian context (Figure 1).

As a result of the proposed matrix, the main goal is to achieve a sustainable built environment which brings a new understanding to the design features used and can offer a modern approach to both architectural design and practice. Moreover, the paper aims at using biomimetic concepts and adaptive techniques to improve flexibility, benefit from the evolutionary information provided by design, extract strategies to obtain the best architectural solutions, act as a catalyst for architectural creativity and improve quality and sustainable design in building envelopes, all of which could help the buildings in Egypt return to a sustainable design path. 


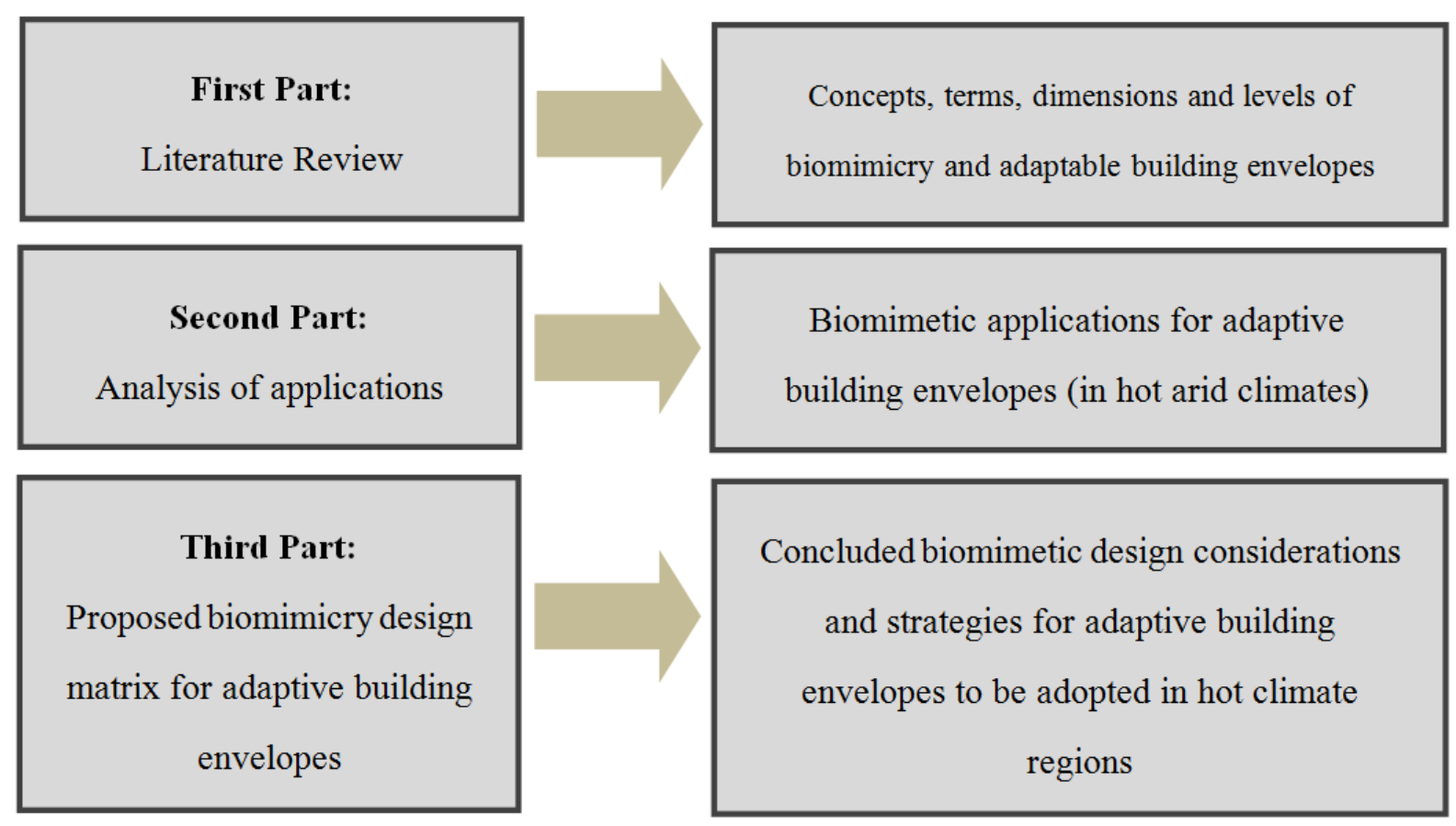

Figure 1. Structure of the study (developed by the author)

\section{Overview and History of Biomimicry}

\subsection{Concept of Biomimicry}

The term "biomimicry" comes from the Greek word, "bio" which means life or nature, and "memesis" which means imitation or imitating nature. Biomimetics, bio-inspired, bionics and other terminologies are often used. In biomimetics, solutions are created by mimicking natural methods, processes and principles. Nature has various means of adjustment approaches which can be used in the design process generally as well as the development of building envelopes particularly. Numerous advantages are recognized by using biomimetics to solve construction challenges which have many benefits including enhancing creativity and innovation, maximizing resources (materials and energy) utilized in buildings, reducing pollutants and emissions, improving thermal comfort and health, minimizing the impacts of urban heat island and developing a base for environmentally conscious growth and development.

Many scientists and researchers attempted to define biomimicry. For example, biomimicry is described by Benyus (1998), as “a modern method for studying nature's innovative strategies and then imitating the design and process to fix a human problem”. Also, according to Guber (2005), biomimicry is "the observation of contrasting fields of biology and architecture which demonstrate creative potentials for architectural challenges [5].

On the other hand, Pederson Zari (2007) argued that biomimicry is a challenge which lacks a consistent concept from many choices available to architects in their projects. As a result, it is crucial to analyse the suitable path to be applied and the best technique in order to effectively promote the advantages of biomimicry. According to Baumeister, biomimicry is "the study of nature, its patterns, processes, mechanisms and components to emulate or to be inspired by nature in order to solve human problems". Scott and Vare (2012), provide a different definition for biomimicry which is "the study of mimicking natural processes and models to produce innovative industrial products" [6]. Moreover, according to Lipholt (2019), biomimicry is "an approach to creativity that investigates sustainable solutions to human problems by imitating nature's time-tested trends and strategies" [7].

As a result discussing the previous concepts and definitions of biomimicry, it is observed that it was first considered as a mere study of nature's ideas and imitating its design and process to solve a problem. Then, it became an important feature and technique in architectural design. Lately, biomimicry became a creative sustainable solution to environmental problems using innovative design strategies.

\subsection{History of Biomimicry}

Biomimicry has a long history which dates back to 500 B.C., when the Greek thinkers looked to natural creatures as examples for inspiring a cohesive equilibrium and a balance between the sections of a building that is compatible with traditional standard of beauty. Later, in 1482, Lenardo Da Vinci was influenced by the flight of birds to create a flying machine which is considered as a primary application of biomimicry. Also, it aided in the 
construction of the first model of the Wright Brothers' aeroplane in 1948. The Crystal Palace in Chatworth in England (Figure 2), was designed by Sir Joseph Paxton and focused on the study of the giant Amazonian water lily laves [8].

Bionics was invented by Jack E. Steele in 1958 and he described it as "the study of natural processes or their equivalents". Though, the word "biomimicry" was discovered in 1982. Janine Benyus, an author and a scientist, presented the word in her book "Biomimicry: Innovation inspired by Nature” in 1997. In 2005, Bryony Schwan and Janine Benyus cofounded the Biomimicry Institute. Then, Chris Allen joined Benyus and Schwan in 2007 to help create "Ask Nature", the world's fastest digital library featuring a collection of natural solutions [5].
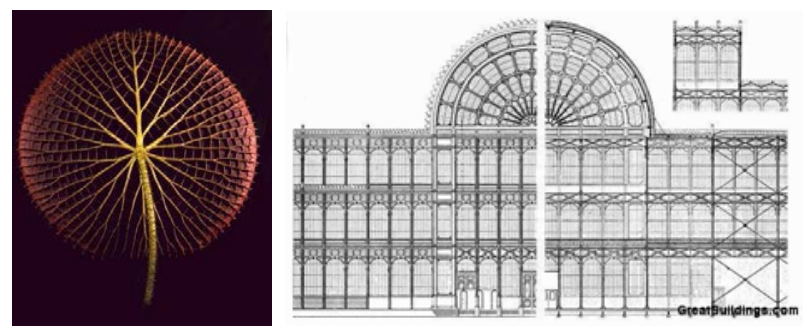

Figure 2. The Crystal Palace was inspired from the water lily laves

\section{Design Approaches of Biomimicry}

Biomimicry is a rapidly expanding area of study in engineering and architectural design. It provides innovative as well as inspiring ideas while developing sustainability in the built environment. Approaches to biomimicry as a design technique usually consist of two groups direct and indirect. On the one hand, the direct approach identifies the user's need or design challenge and then looks at how other species or systems fix it, known as "design looking to biology". On the other hand, the indirect approach identifies a certain pattern, action or feature in an organism or environment and incorporating it into human designs is termed as "design is influenced by biology" [8].

\subsection{Problem-Based Approach (Design to Biology)}

The problem-based method depends on the selection of objectives and design constraints. It is driven from biological inspiration through the development of several non-linear or adaptive measures. In this approach, the designers find alternatives through realization of the challenge. This helps the biologists in matching the design dilemma to an organism that has addressed a similar issue [5].

Daimler Chrysler's prototype Bionic Car is an example of this approach (Figure 3). The design of the car is influenced by the box fish (ostraction meleagris), that is remarkably aerodynamic. The chassis and the structure are both biomimetic have been created using a computer simulation approach focused on how plants may develop in ways that reduce loads on buildings. The resultant building has a skeleton appearance (large volume and small wheels) and material is only distributed to the most critical areas [9].

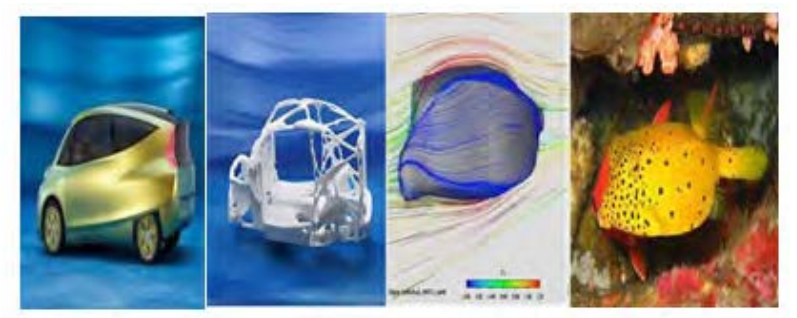

Figure 3. Daimler Crysler's car design was inspired by the shape of box fish and the way trees grow

\subsection{Solution-Based Approach (Biology to Design)}

The "biology influence design", "bottom-up approach" or "solution driven biological inspired design" are different terms used to describe this method. This model is used when the design method depends basically on the scientific information of scientists and biologists rather than human design issues.

For example, the experimental observation of the lotus flower emerging clean from swampy waters, contributed to several design developments that include Sto's Lotusan paint making structures to be self-cleaning (Figure 4).

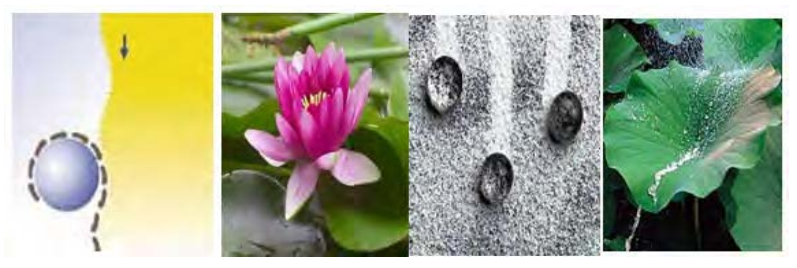

Figure 4. Clean Lotus flower from swampy waters 


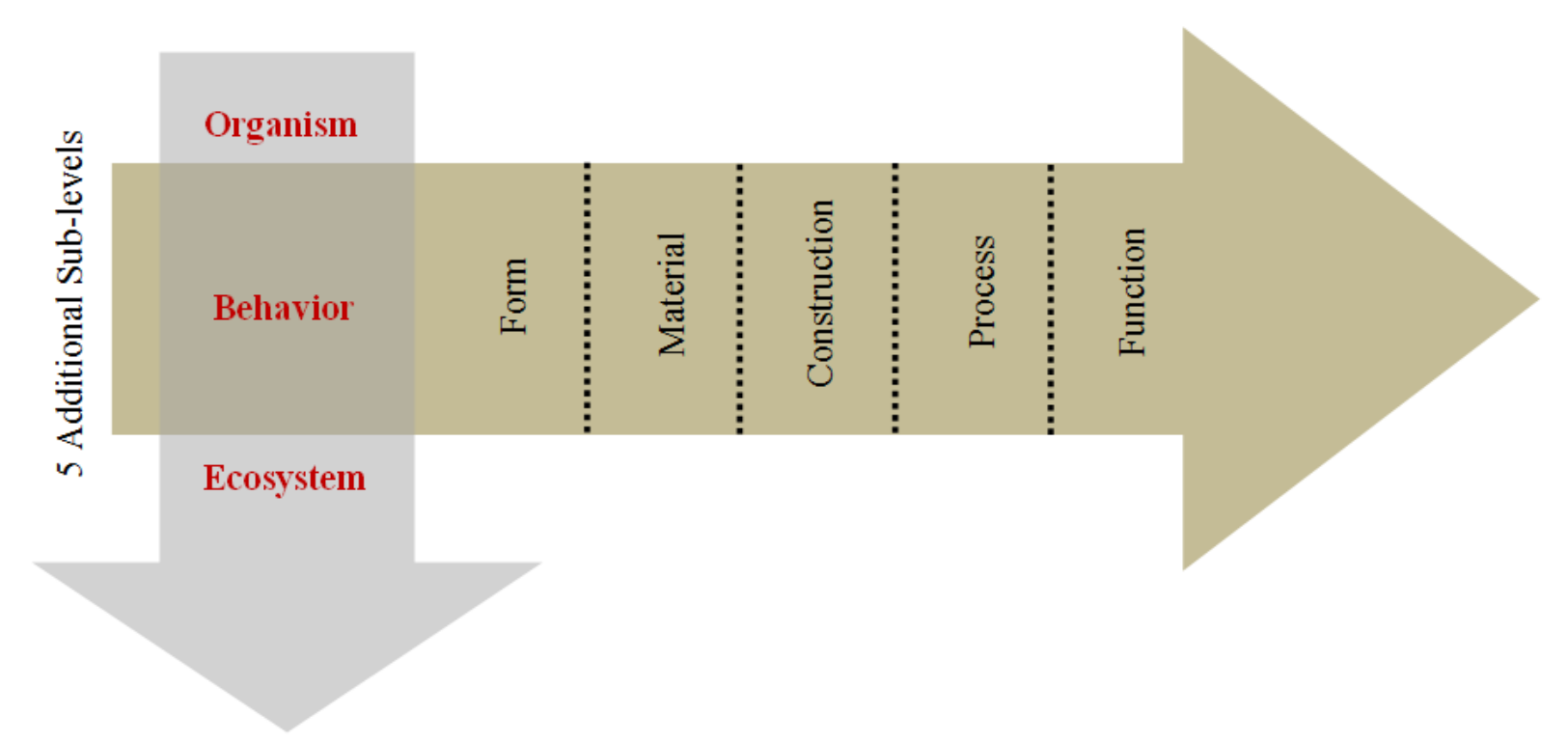

Figure 5. Levels of biomimicry (developed by the author)

\section{Basic Levels of Biomimicry}

There are three fundamental stages of biomimicry, according to Pedersen Zari (2007), organism, behavior and ecosystem (Figure 5). The organism level corresponds to a single organism such as a plant or an animal which may or may not be capable of replicating the organism partially or entirely. This means to imitate the characteristics of an organism, such as its shape, visual form, structure, material and morphological characteristics. To put it in another way, it is the copying of an organism design. The second level is mimicking behavior which may involve copying a feature of performance of an organism or interaction with its environment. The third level involves mimicking of the entire ecosystem and the typical principles that enable them to work effectively. There are five more mimicry measurements for each of these levels. For example, the design is biomimetic in terms of what it looks like (form), what resources are used in construction (material), how it is made (construction), how it works (process) or what it is able to do (function) [10].

From the previous study, it is pointed out that, there is a slight overlap between human design strategies and techniques employed in nature, given that they both live in the same context and have access to the same resources. The inspiration from nature can be observed in two aspects:

- to recreate the concept and to find a form.

- to apply design thinking to the process of emergence of a living entity (material, form, structure, ......etc.).

It is critical to comprehend how each living organism has its own functionality for building a nest surviving in its surrounding and maintaining its conditions while causing no harm to the surrounding environment. The presence of these natural forms influenced architects and designers to study and research biology and ecology in order to harness the nature's way of building in a global network of harmony, with the aim of achieving a sustainable and ecological built environment. In other words, this is a way for buildings to blend with nature in innovative and renewed ways making contexts healthy for occupants [11].

\section{Adaptive Building Envelope}

\subsection{The Envelope of a Building}

Buildings are described as constructions of identified spaces which keep occupants as well as their property safe from the outside environment, especially from severe climatic conditions like excessive sun radiation, wind, humidity and rain. Buildings were developed from simple shelters to complex structures that were modified to their surroundings, where various features have appeared as a result of the need to improve comfort and quality of life.

The basic elements of a building envelope are walls, roofs, floors and windows. They reflect an interaction between the outside environment and the occupied interior spaces where appropriate energy savings can be achieved. Environmental factors are constantly changing such as air temperature, humidity, solar radiation, air flow, quality of air and noise pollution. All of these may affect the comfort inside buildings and pose new problems for building envelopes to support occupants' activities and sustain thermal comfort.

There are several researchers who have identified the term building envelope. According to Rankouhi, "it is the boarder from which structures communicate with the surrounding." [12]. It creates surfaces as well as membranes which adjust air, heat, moisture, light and sound and it is considered as the most common feature for maintaining optimal internal conditions that lead to the functions it performs. Similarly, Hoeven, described the 
envelope of a building as the shell or fabric or skin of the structure or the barrier between the interior of a building and the outside [13].

In general, the building envelope is the bridge between the external environmental influences and the internal occupants' needs [14].

\subsection{Adaptation with Nature}

The idea of adapting a building envelope has been given several different names such as interactive, dynamic, responsive, ... etc. The reason for this is because it concisely changes its performance over time in response to changing external factors and performance demands. The relation between inside and outside in adaptive building envelopes is characterized by the need for high efficiency, energy control and formal and visual expressions of the building.

In nature, the envelope adapts with changing environmental factors and allows buildings to be responsive and react efficiently to environmental stimuli, based on its ability to change or resist external conditions.

Adaptive building shell is a building layer that plays a distinctive role between the exterior and interior space and aids to provide ideal comfort conditions for occupants by ensuring the energy conservation of the building as a contribution to sustainability of built environment [15].

To summarize, building envelopes act as an interface, adjusting to local conditions while still measuring interior requirements. To put it simply, in order to achieve the fittest of a building envelope, it should be adapted to its specific context of location, from climate to use inhabitation [16].

The envelope is similar to the natural skin in organisms where the structure meets the environment and will need to fulfil visual, functional, architectural and comfort goals. Thus, it is a vital component of the overall framework affecting design, usage, structure and other building systems.

Table 1. Common features of biomimetic adaption for building envelopes (developed by the author)

\begin{tabular}{|c|c|}
\hline $\begin{array}{c}\text { Common } \\
\text { features for } \\
\text { optimal internal } \\
\text { conditions } \\
\end{array}$ & $\begin{array}{c}\text { Biomimetic adaptation for building } \\
\text { envelope }\end{array}$ \\
\hline Heat & $\begin{array}{l}\text { Adapt to changing conditions and a } \\
\text { continuous incorporation to ensure enduring } \\
\text { performance. }\end{array}$ \\
\hline Air & $\begin{array}{l}\text { Investigate and engage in strategies that } \\
\text { promote both development and growth. }\end{array}$ \\
\hline Light & $\begin{array}{l}\begin{array}{l}\text { Take advantage of resources and } \\
\text { opportunities. }\end{array} \\
\end{array}$ \\
\hline Water & $\begin{array}{l}\text { Fit into and integrate with the surrounding } \\
\text { environment. }\end{array}$ \\
\hline
\end{tabular}

\section{Applications of Biomimicry on Building Envelopes in Hot Arid Climate}

This paper investigates nature and how it adjusts to the surrounding hot temperature, addressing the issue of increasing cooling loads and energy use in buildings. The following applications present biomimetic solutions for different building envelopes which can be integrated into new building designs to act like living organisms and to achieve existing demands such as being adaptable to the context and to obtain all of its energy needs from nature.

This section of the paper introduces an observational analytical study for various applications that have used biomimetic methods within the building envelope to reduce the consumption of energy while concentrating on sustainable systems and approaches with the aim of developing a biomimicry design matrix that imitates properties from several natural organisms to meet the desired goals.

\subsection{Applications}

\subsubsection{Eastgate Center, Zimbabwe}

The Eastgate Center designed by Mick Pearce is a mid-rise shopping centre and office block. The complex consists of two buildings that shelter an interior atrium (Figure 6). The building is designed to ventilate and cool itself entirely by natural means which is inspired by self-cooling mounds of African termites within thick insulating walls. The structure is partially based on passive ventilation systems and temperature control methods similar to those in the termite mounds. Despite regular temperature fluctuation from $40 \mathrm{C} 0$ to less than $0 \mathrm{CO}$, the termites can maintain a constant internal temperature of $30 \mathrm{C} 0$. This is accomplished by generating and sustaining a draft of air from low openings to the top holes which is called "stack effect". The termites regularly twist these openings for optimal results and they sometimes add wet mud which aids the cooling system by evaporation.

To keep temperature mild, heat gain is reduced by using thick insulating walls, building mass, limiting glazing and deep overhangs. The thick building walls in the underground floor trap heat from the air and human activity throughout the day. At night, cold air is admitted into the bottom of the building which begins the convective flow of the hot daytime air through roof openings. This cold air is collected, stored and then circulated in work places in the next day through hollow floors and baseboard vents [8].

As a result, Eastgate consumes $90 \%$ less energy for cooling than similar sized structure. The mimicry here is process mimicry where air is moved in such a way that temperature within the building remains stable [17]. 


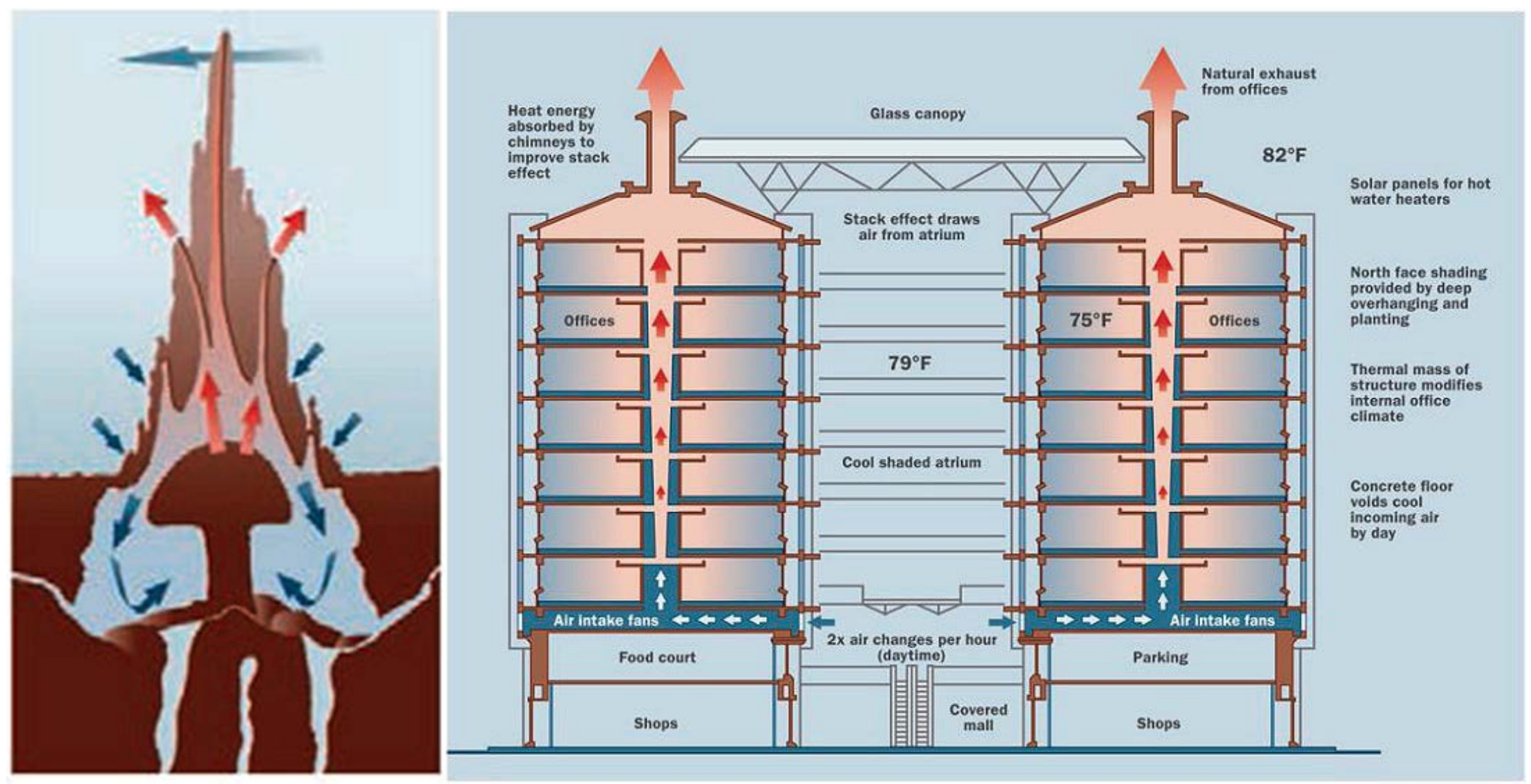

Figure 6. The inspiration of Eastgate Center from the African termite mounds 


\subsubsection{Ministry of Municipal Affairs and Agriculture Office} (MMAA), Qatar:

The MMAA building is based on the cactus shading properties (which conducts transpiration at night rather than during the day) where it preserves water by adding sunshade on the exterior of the building. The shading devices open and close in response to the solar radiation is determined by the perception of the cactus transpiration. These shades serve as filters for the sunlight that enters the spaces and can automatically fluctuate up and down, depending on the desired interior temperature, to control the amount of sunlight and heat that are required to be transmitted into the space (Figure 7).

In addition, other ecological systems are used to filter unclean water. Each natural system separates pollution in water based on the materials it consumes and what they require to survive. Those ecological systems depend on "the use of helpful bacteria, fungi, plants, snails, clams and fish which grow by breaking down and digesting pollutants". These innovative solutions help the building to reduce the amount of artificial cooling needed for proper operation while still offering a sustainable solution.
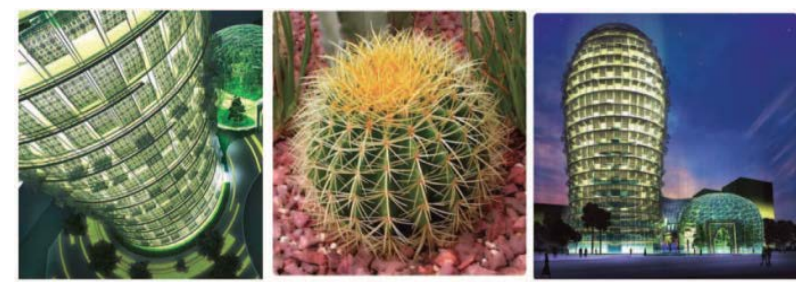

Figure 7. The inspiration of MMAA building from the cactus spines

\subsubsection{The Council House 2 (CH2), Melbourne:}

Another example is Melbourne's Council House 2. It is a sustainable building that was constructed by City of Melbourne with collaboration of Mick Pearce Inc. The design of the building is very creative, as it was inspired by the bark of a tree that focused on connecting the structure to its surrounding ecosystem and living organisms (Figure $8)$.

The use of biomimicry is evident through the whole structure. For example, the west façade resembles the skin of the tree that would regulate the outdoor temperature, however the north and south facades are influenced by the bronchi of the tree. These serve as wind pipes and allow the installation of air ducts on the outside of $\mathrm{CH} 2$. The envelope acts as a buffer surface which captures and filters light and air in the ventilated moist space behind [18]. The design concept applied is passive cooling and heating techniques to minimize the use of energy in intensive heating, ventilation and air conditioning systems (HVAC) which results in greenhouse gas emissions. In the $\mathrm{CH} 2$ building, this system was represented by a series of ventilation stacks (vents) in the north and south facades, managed window openings (pores) and precast wavy concrete ceiling (soil). The air vents are ideally located on the northern side which is the most sun-exposed and the southern façade which is the least sun-exposed. The warmer the air gets in the northern outlets more easily it rises out and gets substituted by cold air from the southern outlets. To further promote this process, the vents on the northern façade are painted with dark colour to absorb more heat, creating a trombe wall effect and the outlets on the southern façade are painted with a light colour to reflect heat [19].

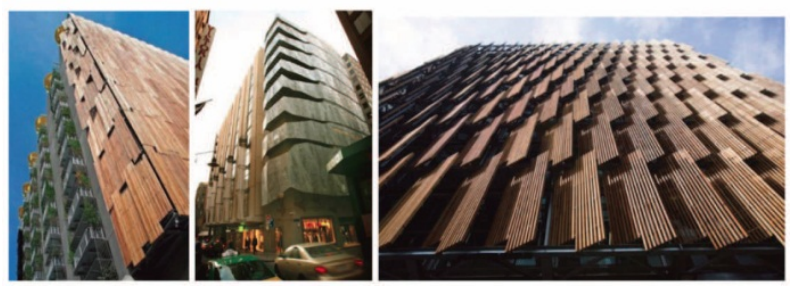

Figure 8. The west and north facades of $\mathrm{CH} 2$

\subsection{Results: Environmental Adaptation Principles for Biomimetic Applications}

The core idea and transition from the natural world to the engineering domain can be transferred through understanding basic concepts such as composition, behavior and ecology. Distinguishing the levels at which biomimicry can be used in architectural design is also important, where information from an organism, behavior or an ecosystem can be discussed. In this paper, it is necessary to compare the case studies and their goals to conclude a biomimetic adaptive building envelope design considerations.

The previous examples considered building typologies, the natural influence, their use in architectural design and how they addressed challenges and solved it using different design solutions (Table 2). Adaptation strategies from several sources have been examined and analyzed such as heat, air, water, ... etc.

\section{Establishing a Biomimicry Design Matrix for Building Envelopes}

An analytical study of relevant techniques and applications was carried out to explain the importance of building envelopes and to compare the various methods and physical characteristics implemented in building envelopes and how they reacted effectively to achieve notable and outstanding performance in buildings and minimize energy consumption through biomimetic approaches [20]. The applications focused on a variety of natural organisms and systems that use unusual techniques to resist harsh environmental conditions. 
Table 2. Principles of adaptation for biomimetic applications (developed by the author)

\begin{tabular}{|c|c|c|c|c|}
\hline $\begin{array}{c}\text { Design } \\
\text { Concept }\end{array}$ & & $\begin{array}{c}\text { African termite } \\
\text { mounds }\end{array}$ & Cactus Spines & A tree bark \\
\hline Approach & & Design to biology & Design to biology & Design to biology \\
\hline \multirow{3}{*}{ Level } & Organism & $\checkmark$ & $\checkmark$ & \\
\hline & Behavior & $\checkmark$ & $\checkmark$ & \\
\hline & Ecosystem & & & $\checkmark$ \\
\hline \multirow{5}{*}{ Sub-approach } & Form & $\checkmark$ & & $\checkmark$ \\
\hline & Material & $\checkmark$ & & \\
\hline & Construction & $\checkmark$ & & \\
\hline & Process & $\checkmark$ & $\checkmark$ & $\checkmark$ \\
\hline & Function & $\checkmark$ & & $\checkmark$ \\
\hline \multirow{4}{*}{$\begin{array}{c}\text { Biomimetic } \\
\text { design } \\
\text { considerations }\end{array}$} & $\begin{array}{c}\text { Heat } \\
\text { (Avoiding heat gain, thermal control and } \\
\text { energy saving) }\end{array}$ & $\checkmark$ & $\checkmark$ & \\
\hline & $\begin{array}{c}\text { Air } \\
\text { (Cooling and natural ventilation) }\end{array}$ & $\checkmark$ & & $\checkmark$ \\
\hline & Lighting & & $\checkmark$ & $\checkmark$ \\
\hline & $\begin{array}{c}\text { Retaining water } \\
\text { (Working with the natural environment) }\end{array}$ & $\checkmark$ & $\checkmark$ & \\
\hline
\end{tabular}

In this section, the paper attempts to define the need for design considerations that can be applied to the building envelope to change it to dynamic interactive thermal skin capable of regulating natural ventilation, acting as a cooling device, controlling light and enhancing visual comfort.

Buildings and natural environments (organisms and their structures), are subjected to varying environmental factors that require managing of heat, air, water and light. Some species control their environment through their skins which function as an environmental filter, while others manage their environment through their structures which use the building envelope as a medium, rather than a barrier, opens up innovative design possibilities, where efficient elements are important.

Egypt enjoys a typical desert climate, hot and arid. The desert is the predominating element covering almost the entire surface of Egyptian context. Deserts are characterized by environmental low relative humidity, irregularity and unpredictability of precipitation and high temperature, especially during daytime and summer months.

These harsh environmental characteristics create difficult conditions for living organisms, plants, animals and humans. In spite of these harsh climatic conditions, numerous and different means of adaptation methods to hot and arid climate are developed and used by most living desert organisms. The majority of them develop different means and systems that reply to two main factors: high and fluctuating temperature and extremely low water availability.

To design an adaptive building envelope, a biomimicry design matrix is proposed. The matrix follows several steps starting from the problem to design solutions that represent the physical characteristics and considerations that can be adopted in buildings.

Firstly, the matrix suggests defining the human needs and environmental problems, stating goals, objectives, limitations and constraints. Secondly, it deals with the nature through its function, process, how they are applied and carried out. Thirdly, is the main stage of the matrix which is the solution using biology to design approach. It concentrates on six morphological features with their solutions which are:

Heat that provides thermal comfort and reduce energy demand inside buildings through applying different considerations such as suitable building orientation, massive and thick walls, passive cooling techniques through cross and stack ventilation.

Air that supplies natural ventilation and improve indoor air quality through adaptable use of openings that suit hot climates.

Water that provides natural resources to the building through conserving its resources, recycling and reusing in different needs.

Light that controls solar radiation by balanced illumination to prevent glare through adaptive orientation of windows, the use of dynamic sunshades and louvers and specifying the type of glazing.

After applying the previous adaptive physical characteristics of living organisms and design considerations into building envelopes, it this may save materials and energy, achieve more functional and sustainable solutions, lower costs and increase performance and durability, also serving as a tool to achieve a sustainable built environment to develop an innovation engine in Egypt (Figure 9). 


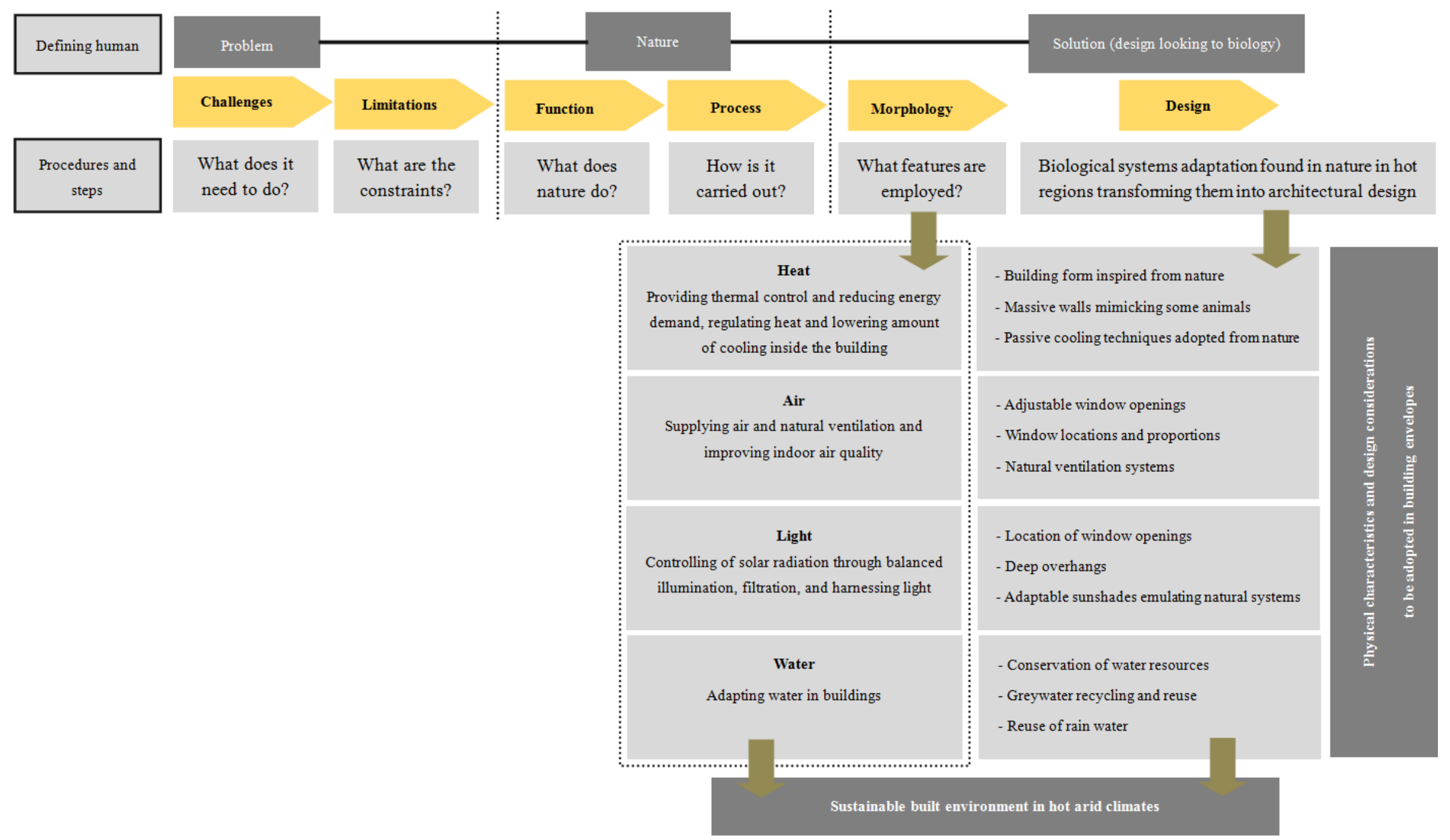

Figure 9. A biomimicry design matrix for the adaptation of building envelopes (developed by the author) 


\section{Discussions and Conclusions}

For billions of years, nature has evolved and has created processes that are extremely efficient and appropriate for the proposed functions. Imitating nature has been applied for a long time that results in numerous developments in a variety of disciplines. This method was recently developed and controlled under the word "biomimicry". Architecture was one of these areas that attempted to mimic nature in order to promote and develop its functions. It started with copying figures, forms and buildings. By the end of the twentieth century, it became possible to emulate natural processes and ecosystems in buildings. This method helped in the discovery of new approaches, principles and design considerations that can be used to improve and adapt building systems to the surrounding conditions.

Biomimicry has proven to be an eco-friendly method for creating energy efficiency in building envelopes. It is a problem-solving technique that has effectively handled several environmental problems in the built environment through architectural design.

The paper has analysed different applications that presented envelopes which include various techniques of adaptation methods in hot climate in terms of physical features, behavioural responses and cooling processes. When these principles were applied to building facades in hot climate, facades were able to cope with climatic changes, particularly natural ventilation to serve as an adjustable layer able to cool interior spaces and natural lighting to control solar radiations that serves as a flexible membrane suitable for light filtration. These methods introduce the idea of sustainable building that is adaptable and can control the exterior climate.

The main goal of the study is to demonstrate how successful and sustainable solutions known as "bio-inspired solutions" can be used to enhance the thermal behaviour of buildings, particularly in summer, by improving the building envelope.

The paper has verified how the application of biomimicry concepts and adaptive approaches from natural organisms, processes and ecosystems can enhance the adaptive behaviour of building skins. It concluded a biomimetic design matrix for adaptive building envelopes that could be used by architects and designers through the design process of buildings especially in hot arid climates (with a special attention to the Egyptian context).

First, the matrix starts by defining the key functions appropriate for both buildings and systems in nature, then identifying the natural systems that fulfil these functions and place gathered data into their physical and environmental settings together to be considered when implementing a design approach to building envelopes. Natural systems create specific morphological configurations that enable them to interact with their immediate environment in the most efficient way. It ends up that morphology has a significant impact on how nature analogues change to adapt to the environment, serving as a multi-functional interface for regulating heat, air, water and light. As a result, morphology can be used as a suitable foundation for biomimetic building envelopes that respond to changing climatic conditions.

When looking for solutions or analogues in nature, it is a generally a growing practice in research, nevertheless realistic examples to buildings for environmental adaptation as they are still minimal. The study aims at developing innovative design considerations inspired by nature to improve the environmental adaptation of building systems particularly building envelopes.

Finally, the application of biomimicry opens many research fields as the following:

- Nature is the most significant teacher which can teach about systems, materials, methods, structures and aesthetics.

- Biomimicry can be used to integrate architecture products with the environment, in addition to the efforts to protect the environment through rationalization of energy systems as well as the reduction of pollution by being part of the architectural product of the ecosystem.

- To obtain efficiency in building design, expanses and materials and to identifying energy needs.

\section{REFERENCES}

[1] Urge-vorsatz, D., Cabeza, L., Serrano, S., Barrenche, C. and Petrichenko, K. Heating and cooling energy trends and drivers in buildings. Renewable and Sustainable Energy Reviews, 41, 85-98, 2015

[2] Sang, X., Pan, W. and Kumaraswamy, M. Informing energy-efficient building envelope design decisions for Hong Kong. Energy Procedia, 63, 123-131, 2014.

[3] Hraska, H. Adaptive Solar Shading of Buildings. International Review Application Science Engineering, 9(2), 107-113, December 2018.

[4] Bouabdallah, N., M'sellem, H. and Alkama, D. Biomimicry as an Approach for Sustainable Architecture: Case of Arid Regions with Hot and Dry Climate. Technologies and Materials for Renewable Energy, Environment and Sustainability, AIP Publishing, August 2016.

[5] Radawan, G., Osama, N. Biomimicry an Approach for Energy Efficient Building Skin Design. Procedia Environmental Sciences, 34, 178-189, 2016.

[6] Scott, W. and Vare, P. Biomimicry. The World We'll Leave Behind: Grasping the Sustainability Challenge, 222(225), January 2018.

[7] Lipholt, N. (2019). Biomimicry-Where Nature is changing Innovation. Bachelor Thesis submitted to the University of Twente, Netherlands.

[8] Nour El Din, N., Abdou, A. and Abdel Gawad, I. Biomimetic Potentials for Building Envelope Adaptation in Egypt. Procedia Environmental Sciences, 34, 375-386, 2016. 
[9] Vincent, J., Bogatyrev, O., Bowyer, N. and Pahl, A. Biomimetics-its practice and theory. Journal of the Royal Society Inerface, April 2006.

[10] Zari, M. Biomimetic Approaches to Architectural Design for Increased Sustainability. Sustainable Building Conference, Auckland, 2007.

[11] El Razaz, Z. Biomimicry inspired adaptive Building Envelope in Hot Climate. Engineering Research Journal, 166(17), A1-A17, June 2020.

[12] Rankouhi, A. Naturally Inspired Design: Investigation into the application of biomimicry in architectural Design, 2012.

[13] Hoeven, M. Technology Roadmap: Energy Efficient Envelopes. International Energy Agency. France, 2013

[14] Grasso, A. and Basso, P. Adaptive Building Skin Structures. Smart Materials and Structures, 19(12), 2010.

[15] Karakoc, E., Cagdas, G. A Data-Driven Conceptual Framework for Climate Adaptive Building Shell: A Hybrid Control Strategy. Civil Engineering and Architecture, 9(2),
427-438, 2021.

[16] Oztoprak, Z. A Biomimetic Perspective on (Retro) fitting of Building Envelopes. A Ph.d thesis submitted to the Graduate School of Natural and Applied Sciences, Middle East Technical University, Turkey, February 2018.

[17] Abdul Rahim, A. Biomimicry in Environmental Architecture: Exploring the Concept and Methods of the Bio-inspired Environmental Architectural Design. Master thesis submitted to Faculty of Engineering. Cairo University. Egypt, July, 2010.

[18] Steadman, P. The Evolution of Designs-biological Analogy in Architecture and Applied Arts. Oxon, Routledge, 2008.

[19] Mohamed, N., Bakr, A. and Hassan, A. Energy Efficient building in Smart Cities: Biomimicry Approach. REAL CORP2019 Proceedings. 24th International Conference on Urban Development, Regional Planning and Information Society, 257-267, 2019.

[20] Dash, S. Application of Biomimicry in Building Design. International Journal of Civil Engineering Technology (IJCIET), 9(2), 644-660, February 2018. 